\title{
INTERNET ADDICTION AMONG SECONDARY SCHOOL STUDENTS CONDITIONED BY GENDER AND AGE
}

\author{
Igor LUKIĆ 1 , Nikola SAVIĆ2*, Ivana VUKOSAVLJEVIĆ ${ }^{3}$, Nevena RANKOVIĆ4, Dragica RANKOVIĆ ${ }^{5}$ \\ ${ }^{1}$ Schoen Klinik, Bad Staffelstein, Deutschland \\ ${ }^{2}$ Singidunum University, Faculty of Health and Business Studies, Department of Health Studies, Valjevo, Serbia \\ ${ }^{3}$ Academy of Educational and Medical Vocational Studies, Department of Ćuprija, Serbia \\ ${ }^{4}$ University of Novi Sad, Faculty of Sciences, Department of mathematics and informatics, Serbia \\ ${ }^{5}$ Union University, Faculty of Computer Science, Department of Mathematics, Belgrade, Serbia
}

\begin{abstract}
Modern forms of addiction are present very much in adolescents today. Internet dependency is a form of addiction that manifests itself as an individual's state of affairs. The use of the Internet has become the most important activity in life in relation to other everyday tasks and activities, to this extent and in that way, to isolate him from other social activities and to bring harmful consequences both to himself and to his family and the environment. Characteristic cases in adolescents that occur are insomnia, family disagreements, delays in school, or the absence and neglect of school obligations, nervousness, fatigue, physical changes such as neglecting personal hygiene, weight loss or other obesity, and etc. The number of Internet users and their addicts is growing every day. With this research, we want to determine whether it depends on gender and age and to what extent does it exist among high school students.
\end{abstract}

Keywords: Internet addiction, Addictions, Gender, Age

\begin{tabular}{|c|c|c|}
\hline \multicolumn{3}{|c|}{$\begin{array}{l}\text { *Corresponding author: Singidunum University, Faculty of Health and Business Studies, Department of Health Studies, Valjevo, Serbia } \\
\text { E mail: nikolasavicvzs@gmail.com (N. SAVIĆ) }\end{array}$} \\
\hline Igor LUKIĆ & https://orcid.org/0000-0002-0419-2722 & Received: April 08, 2021 \\
\hline Nikola SAVIĆ & https://orcid.org/0000-0002-6687-9455 & Accepted: April 17, 2021 \\
\hline Ivana VUKOSAVLJEVIĆ & https://orcid.org/0000-0002-5000-3774 & Published: September 01, 2021 \\
\hline Nevena RANKOVIĆ & https://orcid.org/0000-0002-9910-5886 & \\
\hline Dragica RANKOVIĆ & https://orcid.org/0000-0002-9910-5886 & \\
\hline
\end{tabular}

\section{Introduction}

In the first part of the paper, the subject and objective of the experimental research are given, which will help us to determine the existence of symptoms that indicate the student's Internet dependence on the tested sample. The second part presents the detailed structure of the selected sample. The third part presents a methodology that will be used in working with the above tests for different types of responses of the students. The fourth part analyzes all the results obtained by comparing two groups of male and female students and then comparing the younger and older group of students. The fifth part is the discussion of the obtained results of the research, based on which the conclusions of the research will be precisely presented (Lukić et al., 2017). The subject of this paper is the implementation of experimental research, which would determine the presence of the most common symptoms that indicate the existence of Internet addiction, or excessive, uncontrolled use of the Internet by secondary school students, ages 14 to 19 . The research will monitor the differences in the responses of male and female students and the differences in responses of younger and older students to each question asked at survey (Grujić, 2020, Bugarski, 2018).
The secondary or adolescent era is the age of great physical and psychological changes, which cause instability and oscillations in the mood and behavior of high school students (Mihić et al., 2021). It is a time when youthful excitement is exchanged with moments of mischief, anger, agitation, and increased sensitivity. There is a need for searching for one's own identity and connecting with other peers (Lepojević, 2011). Today, the Internet is the leading mass media and, for these reasons, significantly influences the socialization of young people, their social behavior, the creation of their own vision of the world and the creation of their own identity. However, when the use of the Internet becomes the most important activity of the student, when his social isolation, depression, neglect of school obligations begins, when separation from the computer provokes unpleasant symptoms, endangers his relationships to the closest or the environment, it can be said that there are symptoms indicating Internet addiction (Jović, 2011, Mitrovic et al., 2014).

The main goal is to examine, based on the research, whether there are symptoms that point to the Internet dependence of secondary school students in the Kolubara district and whether Internet dependency depends on 
the age and the age of the students. To determine on the basis of the obtained empirical data on the degree to which she is present at secondary school age and to what extent is the percentage for female and male students (Sherer, 2019). Investigate and determine, based on the research, in which of the two groups of respondents to the younger or older in the sample, the presence of symptoms is greater, that is, indicates a higher internet dependence and in what percentage (Tsai and Lin, 2017). Finally, on the basis of the obtained results, determine whether there is a need for educating students about the proper use of the Internet and getting to know the consequences of its excessive and improper use (Kimberly, 2017).

\section{Material and Methods}

In our research, 218 students of educational profiles took part in secondary schools in the Kolubara district, divided into two equal groups: I. First group, composed of first and second grade students, all have less than 18 years of age and II. Second group, composed by students of the third and fourth grade, all have over 18 years. The realization of our research was also helped by teachers of the health profession, pedagogues, psychologists and other associates in teaching. The structure of our sample is presented in Table 1.

In order to analyze student responses to the questions asked, the Chi-Square test of independence CS was used. As a null hypothesis we can say that given the opinion, attitude or determination of students does not depend on the gender of students from both groups of students. An alternative hypothesis is accepted or rejected depending on the results obtained in the study using the appropriate Chi-Square test. For questions that have student responses in the form: Students' responses were on the 5-point Likert scale: (1- "never", 2- "rare", 3"occasional", 4- "often", 5 "always"), Mann-Whitney test MWU and Kolmogorov-Smirnov KS test were used within the SPSS program for statistical data processing. As a null hypothesis, we can say that the given opinion and the grade of each student do not depend on half the students from both groups of students. Alternative hypotheses are accepted or rejected depending on the results obtained in the research.

In order to determine whether there are statistically significant differences between male and female students in both groups we used: Mann-Whitney and KolmogorovSmirnov test.

Table 1. Sample sizes and averages

\begin{tabular}{llcccccc}
\hline & & Students (n) & Students (\%) & Males (n) & Males (\%) & Females (n) & Females (\%) \\
\hline \multirow{2}{*}{ I group } & 1. class & 59 & 27.1 & 26 & 44.1 & 33 & 55.9 \\
& 2. class & 45 & 20.6 & 25 & 55.6 & 20 & 44.4 \\
II group & 3. class & 64 & 29.4 & 33 & 51.6 & 31 & 48.4 \\
\multirow{2}{*}{ Total: } & 4. class & 50 & 22.9 & 28 & 56.0 & 22 & 44.0 \\
\hline
\end{tabular}

Table 2. Average grade, standard deviation, values of Kolmogorov-Smirnov test

\begin{tabular}{lcccccccc}
\hline & $\operatorname{Avg}(\mathrm{M})$ & $\operatorname{Avg}(\mathrm{F})$ & $\mathrm{STD}(\mathrm{M})$ & STD $(\mathrm{F})$ & MWU (U) & MWU (p) & KS (D) & KS (p) \\
\hline I group & 2.71 & 2.79 & 0.944 & 1.063 & 1301.500 & 0.733 & 0.347 & 1.000 \\
II group & 2.67 & 2.89 & 1.028 & 0.974 & 1396.000 & 0.190 & 0.850 & 0.465 \\
\hline
\end{tabular}

From the data in Table 2, we can conclude: There are no statistically significant differences between the average grades of male and female students from the first and second group.

\section{Results}

Based on the students' answers from an anonymous survey, we tried to determine the existence of symptoms of internet dependency among male and female students in both groups of respondents. We looked at the following symptoms that indicate the presence of Internet addiction: nervousness, impatience due to the inability to access the Internet, neglect of school obligations due to the Internet, the Internet instead of bad mood, dissatisfaction and discontent disappear due to online, the feeling that all problems disappear on the Internet, headaches, insomnia, and fatigue as a result of excessive use of the Internet. We examined all six symptoms in male and female students in the first and second group, where it is possible to determine the percentage of students' answers to each question asked and compare them, and then determine which students and in which group is the greater the presence of these symptoms.

When asked, if they were using the Internet every day, we got the following answers: in the first group the probability of MWU (P) is 0.656 , and the probability KS (P) is 1.000 , in the second group probability MWU (P) is 0.814 , and the probability KS (P) is 1.000 , which means that there are no statistically significant differences in the responses of male and female students in both groups. The second group assessed the daily use of the Internet with the mean (4.09), and the first group with the mean (3.89), which means that the older students use the internet a little more day by day. Students use mostly mobile internet, the first group, males (38.5\%), females $(45.2 \%)$ and least ADSL (0.9\%), the other group also mobile Internet, males (26.2\%), females (53.1\%), 2.9\%). 
There are no statistically significant differences in the responses of male and female students in both groups. Students were asked from which place they most often access the Internet, and it can be concluded that the highest percentage of students access the Internet from any place, in the first group: males $(27.9 \%)$, females $(22.1 \%)$, while in the second older group it is the percentage of (26.3\%) for males and (16.7\%) for females. There are no statistically significant differences in the responses of male and female students in both groups. The highest percentage of students in the first group, males $(39.4 \%)$, females $(44.2 \%)$, in the second group males (43\%), females (40.3\%) spend a day on average from 4 to 8 hours. A large percentage of them (11.5\%) in the first group and $(12.3 \%)$ in the second group spent daily and more than 8 hours on the Internet. The very small percentage of students, in the first group males $(2.9 \%)$, females $(1.9 \%)$, in the other group, males $(2.6 \%)$, females $(0.8 \%)$ use the Internet less than 4 hours a day. There are no statistically significant differences in the responses of male and female students in both groups. The purpose of using the Internet is different in the first group. The highest percentage of students uses the Internet for communication and social networks, males $(17.3 \%)$ females $(32.7 \%)$ in the first group, and in the second group for the same purpose, the percentage for males is $(24.6 \%)$, and females $(24.6 \%)$ We can conclude that there are statistically significant differences in the responses of male and female students in the first group, while in the second group there are no significant differences. About $15 \%$ of female students use social networks and communicate over the Internet, while from $7 \%$ to $8 \%$ more male students watch movies, listen to music and play games. There are no statistically significant differences in the answers of male and female students in the second group. It can be concluded that students of the third and fourth grade play fewer games much more, $10 \%$ of male students use the Internet more for learning, and spend less time on social networks.

Students of both groups, regardless of the gender, stay longer on the Internet than they planned, the median value for male students is (2.07), female (2.09), and there are no significant differences in the answers of students of the gender.

Students of both groups, regardless of the gender, meet "virtual" friends and comrades and communicate with them on the Internet, where the median value for male students is (3.28), female (3.29). There are no statistically significant differences in the answers of male and female students. Answers from both groups of students, when is asked about online communication, rather than face-to-face communication, are without significant differences between male and female respondents in the first group, but there are significant differences among students in the second group. Female students in the second group are in a slightly higher percentage of about $5 \%$ on average communicate more with virtual friends over the Internet than male students.
In students' responses to the question of whether they were uncomfortable or harassed on the Internet, there are no statistically significant differences in the responses of male and female students in the first group. There are statistically significant differences in the responses of male and female students when experiencing discomfort or harassment on the Internet in question in the second group. In the second older group, female students in a somewhat higher percentage of about $5 \%$ averagely experience unpleasantness or harassment on the Internet than pupils of the male sex. From the students' answers, we can conclude that there are no statistically significant differences in the responses of male and female students when the time spent on the Internet is greater than with the comrades concerned in both groups. A total of $6.4 \%$ of students "always" stay on the Internet before spending free time with their comrades, and 6\% more in the older group makes it "often". Based on the students' answers, from the first group, we can conclude that there are no statistically significant differences in the responses of male and female students when it comes to nervousness and impatience due to the inability to access the Internet. There are statistically significant differences in the answers of male and female students in the second group when nervousness and impatience due to the inability to access the Internet. Females are 5\% more nervous and impatient than males. A total of $8.7 \%$ of students are "always" nervous and impatient because of the inability to access the Internet, and about 3\% more in the older group makes it "often". We can conclude that there are no statistically significant differences in the answers of male and female students when the neglect of school obligations is due to the excessive use of the Internet in both groups. On average, both groups rated the neglect of school obligations (4.00), which means they often do. A total of $23.4 \%$ of students "always" ignore school obligations due to access to the Internet, and about 3\% more in the older group makes it "often". From the students' answers, we can conclude that there are no statistically significant differences between male and female students when it comes to avoiding bad mood, feelings of helplessness, guilt, anxiety, depression due to excessive use of the Internet in both groups. In both groups, female students are in a slightly higher percentage of about $5 \%$ on average and have more disabilities, feelings of helplessness, guilt, anxiety, depression when it comes to excessive use of the Internet than male students. From the students' answers, we can conclude that there are no statistically significant differences between male and female students when it comes to the emergence of dissatisfaction and dissatisfaction if they are online, in both groups. In female students' answers of the first group, we have a higher percentage of about $6.5 \%$ on average, that dissatisfaction and dissatisfaction disappear when online, compared to male students. We can conclude that there are no statistically significant differences in the 
responses of male and female students in terms of headaches and insomnia after a long-standing presence on the Internet, in both groups. A total of $26.3 \%$ of students "always" have a headache, insomnia after longterm use of the Internet, equally in both groups. We can conclude that there are no statistically significant differences in the responses of male and female students when it comes to happiness and satisfaction on the Internet, and students do not have a positive opinion that all problems are solved by a presence on the Internet in both groups. With the largest percentage of female students, $16.06 \%$ have said that dissatisfaction and discontent disappear when they are on the Internet, but also the smallest percentage of them $0.00 \%$ gave the answer that bad mood can always be replaced by the Internet (Table 3).

Table 3. Percentage of students' answers, on the selected scale, "always" according to the gender of the student, I. group of the students

\begin{tabular}{|c|c|c|}
\hline & "alw & $(\%)$ \\
\hline \multirow{5}{*}{$\begin{array}{l}\text { Nervousness, impatience due } \\
\text { to the inability to access the } \\
\text { Internet } \\
\text { Ignoring school obligations } \\
\text { over the Internet }\end{array}$} & Male & 3.21 \\
\hline & Female & 5.50 \\
\hline & Male & 9.63 \\
\hline & Female & 13.76 \\
\hline & Male & 0.46 \\
\hline \multirow{3}{*}{$\begin{array}{l}\text { Internet instead of bad mood } \\
\text { Disagreement and } \\
\text { dissatisfaction disappear } \\
\text { when we are online }\end{array}$} & Female & 0.00 \\
\hline & Male & 8.72 \\
\hline & Female & 16.06 \\
\hline \multirow{2}{*}{$\begin{array}{l}\text { All problems disappear due } \\
\text { to the use of the Internet }\end{array}$} & Male & 1.85 \\
\hline & Female & 5.05 \\
\hline \multirow{2}{*}{$\begin{array}{l}\text { A headache and insomnia due } \\
\text { to the Internet }\end{array}$} & Male & 8.72 \\
\hline & Female & 9.17 \\
\hline
\end{tabular}

With the largest percentage of female students, $13.03 \%$ of the II. Older group, distress, and discontent disappear when they are on the Internet, but also the smallest percentage of them $0.00 \%$ gave the answer that bad mood can always be replaced by the Internet (Table 4).

Figure representations 1, 2, 3, 4, 5 and 6 give a visualization of each of the tested parameters by gender and age.
Table 4. Percentage of students' answers, on the selected scale, "always" according to the gender of the student, II. group of the students

\begin{tabular}{|c|c|c|}
\hline & "over" & $(\%)$ \\
\hline $\begin{array}{l}\text { Nervousness, impatience due } \\
\text { to the inability to access the }\end{array}$ & I group & 3.21 \\
\hline Internet & II group & 5.50 \\
\hline Ignoring school obligations & I group & 10.55 \\
\hline over the Internet & II group & 12.84 \\
\hline Internet instead of bad mood & $\begin{array}{l}\text { I group } \\
\text { II group }\end{array}$ & $\begin{array}{l}0.46 \\
0.00\end{array}$ \\
\hline $\begin{array}{l}\text { Disagreement and } \\
\text { dissatisfaction disannear }\end{array}$ & I group & 13.00 \\
\hline when we are online & II group & 13.03 \\
\hline All problems disappear due to & I group & 3.21 \\
\hline the use of the Internet & II group & 3.67 \\
\hline A headache and insomnia due & I group & 8.26 \\
\hline to the Internet & II group & 9.63 \\
\hline
\end{tabular}

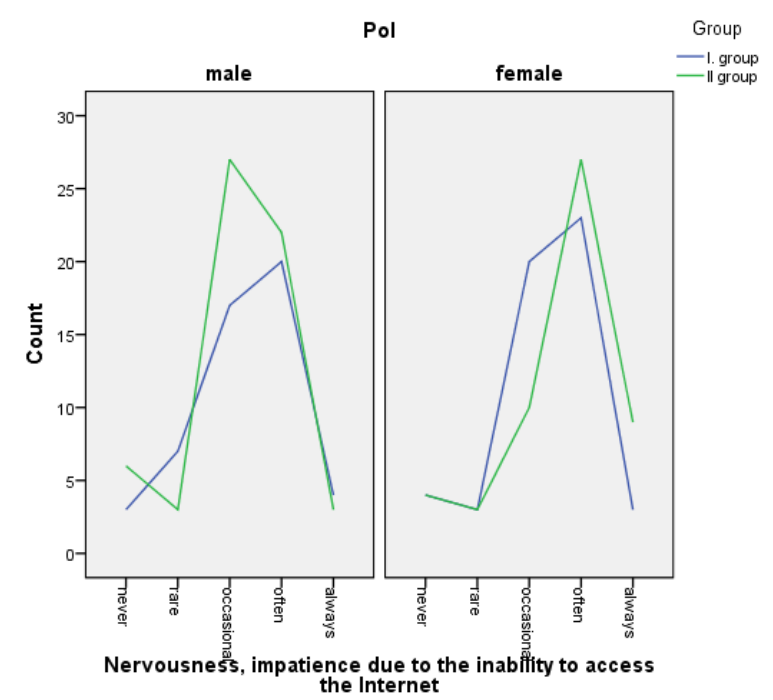

Figure 1. Percentage of students' answers to the question asked by gender and age.

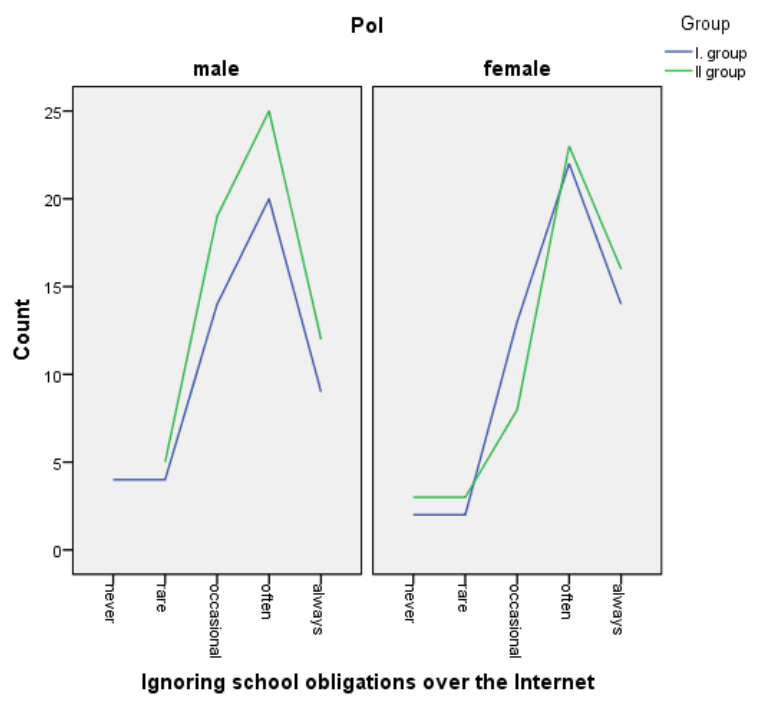

Figure 2. Percentage of students' answers to the question asked by gender and age. 


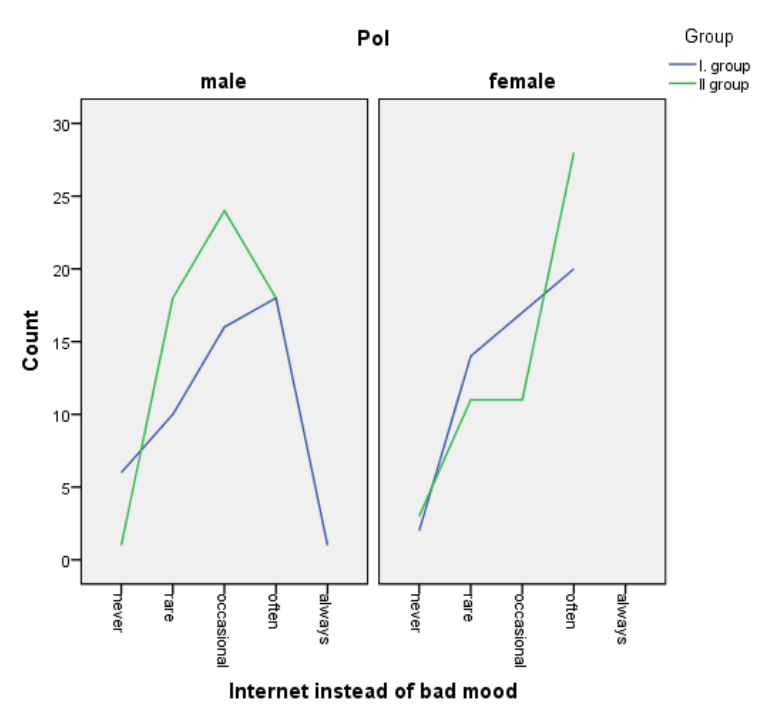

Figure 3. Percentage of students' answers to the question asked by gender and age.

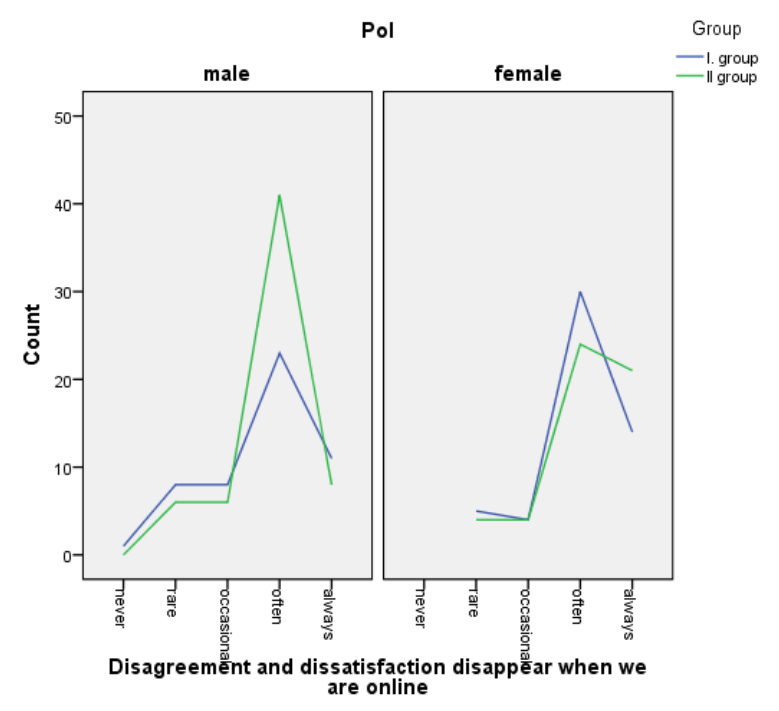

Figure 4. Percentage of students' answers to the question asked by gender and age.

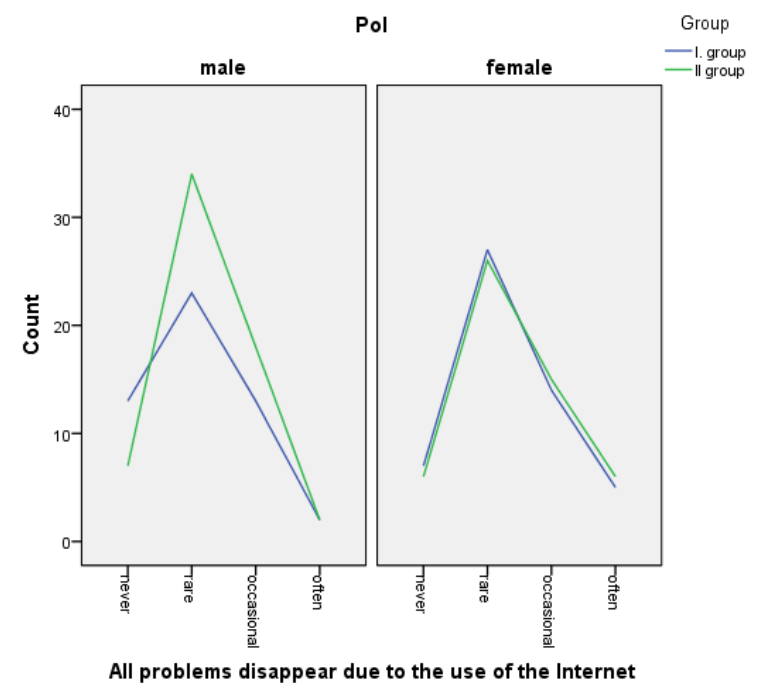

Figure 5. Percentage of students' answers to the question asked by gender and age.

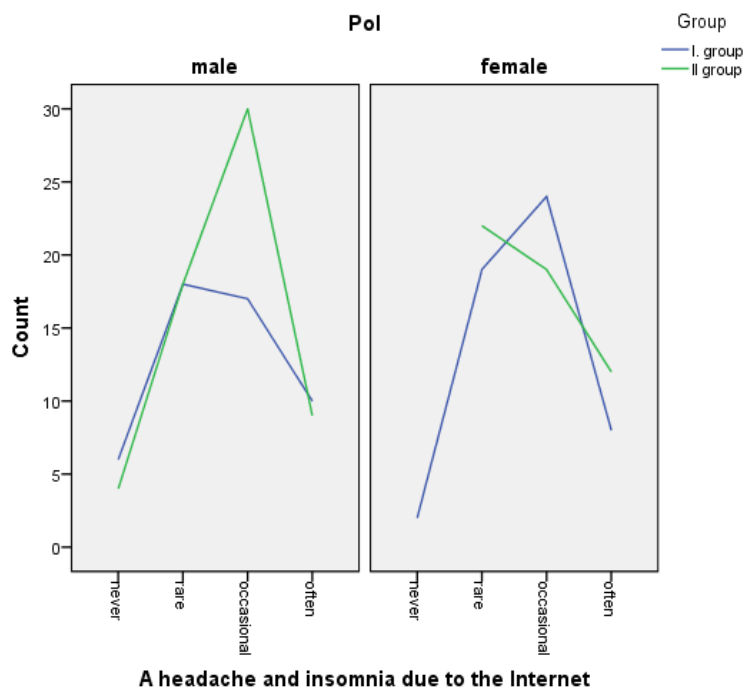

Figure 6. Percentage of students' answers to the question asked by gender and age.

\section{Discussion}

Based on the obtained results of statistical tests it can be concluded that in most of the questions asked there are no significant statistical differences in the responses of male and female students. There are differences in the choice of content offered on the Internet. There are statistically significant differences in the responses of male and female students in the first group. About 15\% more female students use social networks and communicate over the Internet than male students, while $7 \%$ more male students watch movies, listen to music and play games. It can be concluded that third-and fourth-grade students play fewer games, $10 \%$ of male students use the internet more for learning and spend less time on social networks.

There are statistically significant differences in the responses of male and female students when it comes to getting acquainted with virtual friends, in the second group. In the second older group, female students in a slightly higher percentage of about 5\% average acquainted virtual friends over the Internet than male students.

There are statistically significant differences in the responses of male and female students when experiencing discomfort or harassment on the Internet, in the second group. In the second older group, female students in a somewhat higher percentage of about $5 \%$ averagely experience unpleasantness or harassment on the Internet than male students (Fumero et al., 2018).

If we analyze the use of the Internet by years of the students, we get statistically significant differences and that the use of the Internet increases with age. Students of the second group, about $11 \%$ more use the Internet and we can conclude that the use of the Internet increases with increasing age (Przepiorka et al., 2019). A total of $6.4 \%$ of students "always" stay on the Internet before spending free time with their comrades, and $6 \%$ more in the older group makes it "often". 
There are statistically significant differences in the responses of male and female students when it comes to the nervousness and impatience arises from the inability to access the Internet, in the second group. Females are $5 \%$ more nervous and impatient than males (Shubnikova et al., 2017).

A total of $8.7 \%$ of students are "always" nervous and impatient because of the inability to access the Internet, and about 3\% more in the older group makes it "often".

A total of $23.4 \%$ of students "always" ignore school obligations due to access to the Internet, and about 3\% more in the older group makes it "often" (Pan and Yeh, 2018).

In both groups, female students in a slightly higher percentage of about $5 \%$ on average have more disabilities, feelings of helplessness, guilt, anxiety, depression when it comes to excessive use of the Internet than male students. Numerous studies support our data and research results (Fitria et al., 2018).

\section{Conclusion}

Our research showed the presence of all examined symptoms that indicate the existence of internet addiction. With these symptoms due to excessive internet use, there is a certain percentage of students in both groups, but this percentage is about $5 \%$ higher in the older group compared to the younger group, which would mean that the number of students with symptoms indicating Internet addiction increases with age. When we look at the differences between male and female students, the presence of symptoms of internet addiction in females is about $3 \%$ higher than in male students.

Based on the above conclusions, we can assume that high school students have symptoms that indicate Internet addiction. Based on all the presented and presented conclusions, it is necessary to start educating students about the proper and safe use of the Internet and getting acquainted with the consequences of its excessive use. It is necessary to start with moderate and correct use of the Internet from the earliest age, when children start using a computer to play. Acquaintance with the negative consequences for health should be done continuously according to the age of the children, ie the content that they follow the most at that age.

\section{Author Contributions}

All the authors declare that they have all participated in the design, execution, and analysis of the paper, and that they have approved the final version. The ethical aspects and principles of scientific research were respected in the research.

\section{Conflict of Interest}

The authors declare that there is no conflict of interest.

\section{Ethical Approval/Informed Consent}

For the needs of the research, the permission of the competent bodies and the ethics commission was obtained (Research license number 18/19/1).

\section{References}

Bugarski V. 2018. Internet addiction on the way to the new diagnostic category, 1st ed. Autorsko Izdanje, Beograd, Serbia, pp. 5-17.

Fitria L, Ifdil I, Erwinda L, Ardi Z, Afdal A, Sari A. 2018. Exploring internet addiction on adolescents. J Physics: Conference Series, 1114: 012076. DOI: 10.1088/17426596/1114/1/012076.

Fumero A, Marrero R, Voltes D. 2018. Personal and social factors involved in internet addiction among adolescents: A meta-analysis. Comp Human Behav, 86: 387-400. DOI: 10.1016/j.chb.2018.05.005.

Grujić V. 2020. Personality traits and internet addiction. Philosophy, 1: 25-27.

Jović J. 2011. The influence of the dopaminergic system on the Internet addiction, Special Educ and Reh, 7: 3-5.

Kimberly Y. 2017. Internet addiction: A handbook and guide to evaluation and treatme, 3rd ed. John Wiley \& Sons, Hoboken, USA, pp. 30-33.

Lepojevic KM. 2011. The concept and characteristics of Internet addiction. Special Educ Rehab, 10: 4-5.

Lukić I, Ranković D, Ranković N. 2017. The presence of internet addiction among high school students. Zdravstvena Zastita, 46(4): 33-40. DOI: 10.5937/zz17040331.

Mihić V, Lelović G, Olujić V. 2021. Internet behavior, gender, age and introvert effects. Faculty Phil, 1: 5-8.

Mitrovic D, Djordjevic J, Ciric D. 2014. Use of the internet with students in Knjazevac. Timocki Med Glasnik, 39(2): 66-77. DOI: $10.5937 / \mathrm{tmg} 1402066 \mathrm{~m}$.

Pan P, Yeh C. 2018. Internet addiction among adolescents may predict self-harm/suicidal behavior: A prospective study. J Pediatrics, 197: 262-267. DOI: 10.1016/j.jpeds.2018.01.046.

Przepiorka A, Blachnio A, Cudo A. 2019. The role of depression, personality, and future time perspective in internet addiction in adolescents and emerging adults. Psychiatry Res, 272: 340348. DOI: 10.1016/j.psychres.2018.12.086.

Sherer K. 2019. College life on-line: Healthy and unhealthy internet use. J College Stud Devel, 38(6): 655-665.

Shubnikova E, Khuziakhmetov A, Khanolainen D. 2017. Internet-addiction of adolescents: Diagnostic problems and pedagogical prevention in the educational environment. Eurasia J Math, Sci Tech Educ, 13(8): 5261-5271. DOI: 10.12973/eurasia.2017.01001a.

Tsai C, Lin S. 2017. Analysis of attitudes toward computer networks and internet addiction of taiwanese adolescents Cyberpsych Behav, 4(3): 373-376. DOI: 10.1089/109493101300210277. 